\title{
INTERNAL AND EXTERNAL STAKEHOLDERS' IMPACT ON PRODUCT DEVELOPMENT CURRICULUM DESIGN
}

\author{
Hanna LINDSTEN, Petra AUVINEN and Tero JUUTI \\ Tampere University of Technology, Laboratory of Mechanical Engineering and Industrial \\ Systems, Finland
}

\begin{abstract}
This paper is based on research concerning curriculum design work done at Tampere University, Unit of Automation Technology and Mechanical Engineering (former Tampere University of Technology, Laboratory of Mechanical Engineering and Industrial Systems), Finland. The paper examines internal and external stakeholders and their influence on curriculum design work from higher education teachers' point of view. The teachers do not develop curriculum independently of other stakeholders. Instead, the development activity is seen here as a joint effort of both internal and external stakeholders having a common goal of improving curriculum design and practice. In this case, internal stakeholders include the faculty, the students, and the higher education teachers' own community while external stakeholders refer to the higher education policy and the labour market. The aim of the paper is twofold: Firstly, to analyse and make visible what kind of influence various stakeholders have on curriculum design work in product development education, and secondly, to discuss the ways in which higher education curriculum can be improved as a collaborative process between internal and external stakeholders.
\end{abstract}

\section{Keywords: Curriculum design, stakeholders, product development education, competence-based curriculum}

\section{INTRODUCTION}

Curriculum is an important tool for teaching and learning. However, the work related to curriculum design is usually seen as an arduous process taking time away from daily teaching activities. The teaching and research staff's duties, however, include contributing to the process of curriculum change, often initiated by the central management [1]. The benefits of teachers collaboratively producing new knowledge about curriculum and how it should be developed are widely recognised [2] [3]. Fostering active and effective involvement requires that the teachers themselves feel the need to change their practice, are convinced that their effort will bring about that change, and that they are capable of promoting and installing that change [4]. This paper, being a continuation of previous research by Juuti et al. [5] and Nevaranta [6], aims to point out, that in addition to teachers there are also other stakeholders having an impact on curriculum design. Various external and internal stakeholders are taken into account in analysis because the focus of university's corporate culture is moving towards partnership and collaboration with external environment [7]. There are many ways to identify and categorise various stakeholders influencing on curriculum design. For example, based on a study by Matkovic et al. [8], the internal stakeholders consist of the board of directors, the university research and teaching staff, students, and the management of the university. The external stakeholders include the government, potential students, business partners, employers and competitors. In this paper, internal stakeholders contain the university management, faculty management, department management, professors, the students, and the higher education teachers' own community while external stakeholders refer to the higher education policy and the labour market. The teachers have a significant role in curriculum design because they are responsible for executing the curriculum. The paper accordingly presents the higher education teachers' perceptions and understanding on the ways in which various stakeholders influence on curriculum design in the major of Product Development. 


\section{RESEARCH STRATEGIES}

The research strategies used here include qualitative research, educational research, and case study research. Snape and Spencer [9] describe that qualitative research aims to provide "an in-depth and interpreted understanding of the social world of research participants by learning about their social and material circumstances, their experience, perspectives and histories". Many qualitative studies use video or, as in this study, audio data, which are then transcribed into written form. This study is also based on a qualitative approach of educational research. According to Anderson [10] "educational research is the systematic process of discovering how and why people in educational settings behave as they do". Educational research may focus on various aspects of education, including student behaviour, teacher training or social justice. The main purpose of the research is to improve teachers' professional practice and the systems within which they operate to support student learning. [11.] Case study research is an inquiry focusing on describing, understanding, predicting, and/or controlling the individual process, person, group, organisation, industry, or culture [12]. In educational research, the case study provides a means of doing a small-scale investigation of a variety of contexts and situations, ranging from the experiences of individuals to the workings of universities, and from single cases of people, classes or organisations to multiple cases [11]. In this study, specifically, the case is a curriculum development session held at the former Laboratory of Mechanical Engineering and Industrial Systems. As a qualitative case study, this study seeks to understand the uniqueness and complexity of the chosen case as well as its interaction with its contexts [13].

\section{DATA AND METHOD}

The research data was collected from the curriculum development session conducted at the Laboratory of Mechanical Engineering and Industrial Systems on October 2018. The session was primarily organised for the curriculum development purposes and secondarily for the research purposes. The participants in the session were four product development teachers, a facilitator, a researcher, and a research assistant. In the session, the participants aimed at jointly creating a particular flow chart to describe and document the specific learning outcomes as well as the knowledge, skills, routines, and attitudes the students should learn to achieve those outcomes. The flowchart is presented in figure 1 .

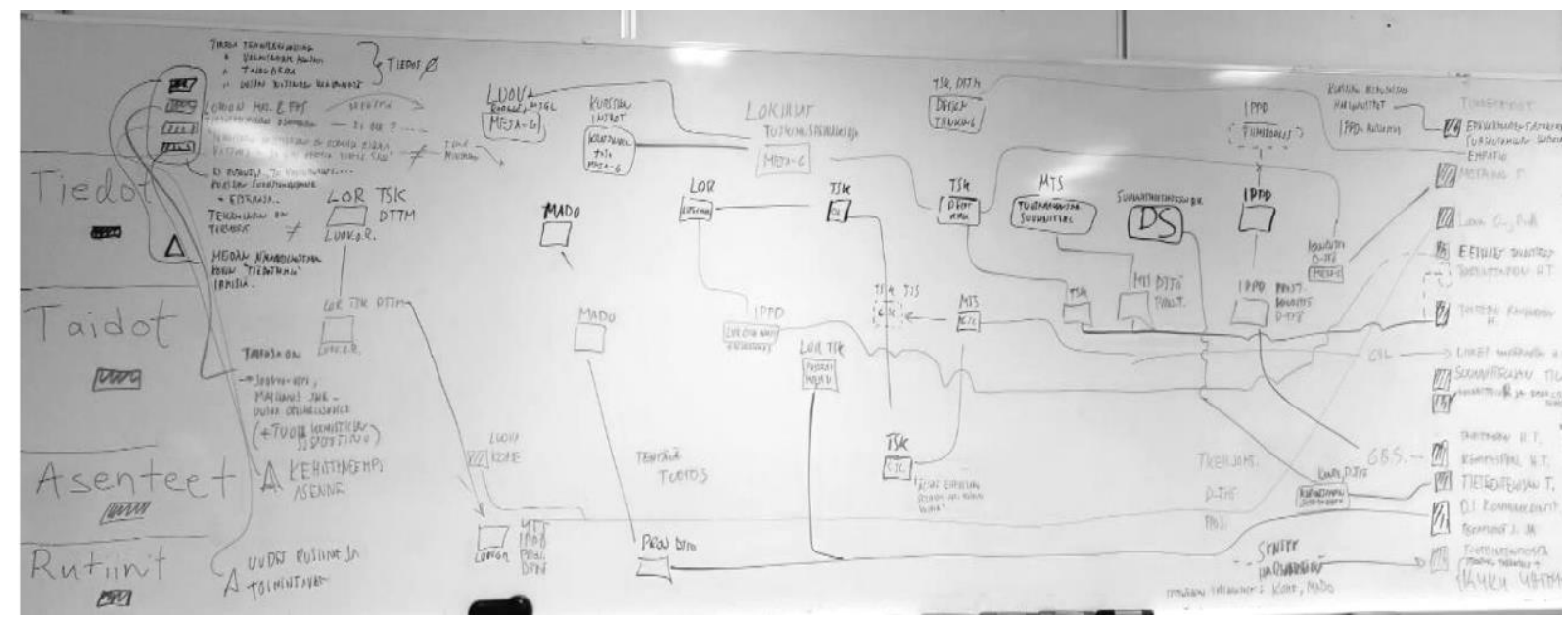

Figure 1. The flowchart created during the curriculum development session. The learning outcomes are visualised as boxes, starting point is on left and student's graduation is on the right. Learning outcome have four types: Knowledge, skills, attitude and routines and they are marked with different colours

The researcher observed the session and intervened with questions about the various stakeholder roles in the curriculum design work. The three-hour session was recorded on an audio tape and then transcribed. The teachers in this study have diverse professional experiences; Brian has worked 15 years in manufacturing industry, 10 years in consulting company and 15 years at the university. Mike has worked 15 years at the university and Jack has 25 years' experience on teaching and 10 years' experience in consulting company. 
The research method used in this study is directed content analysis [14], also called as directed qualitative content analysis [15]. Directed approach to content analysis aims at validating or extending conceptually some theoretical framework or theory [14]. Existing theory and research support the development of the research question and provide predictions about the key concepts or variables as initial coding categories [16]. This has also been referred to as deductive category application [17]. The main advantage of a directed approach to content analysis is that existing theory can be supported and extended. The notion that the researchers may approach the data with an informed, but strong bias is seen as an inherent limitation of this approach. [14.]

\section{RESULTS}

The research results presented here describe the ways in which internal and external stakeholders influence on curriculum design process in the major of Product Development. The results specifically illustrate the product development teachers' perceptions and understanding concerning various stakeholders' role and meaning in the process of curriculum design. Internal stakeholders refer to the stakeholders influencing inside the university, while external stakeholders have an influence from outside the university. Internal stakeholders include the faculty, the students, and the higher education teachers' own community while external stakeholders concern the higher education policy and the labour market.

\subsection{Internal stakeholders}

The faculty together with the whole higher education organisation have a significant role in curriculum design work, which the teachers participating in the session often emphasised. The faculty was also described as a relatively distant authority that sets the conditions to be met. The university administration was seen to restrict the curriculum in its role of being responsible for the issues to be taught. The data revealed that teachers were not even conscious about the new orders set by the administration. The faculty has a dominating role in curriculum work even though it does not take a stand on the content of the curriculum:

$$
\begin{aligned}
& \text { Mike: Here (the assessment guide) it is stated that assessment criteria for the credit } \\
& \text { is based on learning outcomes defined in the curriculum and curricula guide. It is } \\
& \text { a quite challenging trick to define them because learning outcomes would be } \\
& \text { managed but, yet assessment criteria should be defined for the next three years. }
\end{aligned}
$$

Another internal stakeholder are the students, which were also seen to have a significant impact on curriculum design work. The teachers had an opinion that the students have a relatively weak preliminary knowledge and skills when they come to study product development. This must be taken into account when designing curriculum and teaching. Year by year, the students' preliminary knowledge and skills appear to be even weaker, which is why teaching the basic courses is more time consuming than previous years.

What is also challenging in curriculum design work are the students' attitudes and misunderstandings when they come to study at the university. The teachers described that the attitudes they wanted to teach their students are inconsistent with the attitudes of the students starting their studies. As Jack puts it:

$$
\begin{aligned}
& \text { Jack: In the beginning, they have a belief they are not innovative. They have also } \\
& \text { that kind of an attitude that there is a right answer to every question. }
\end{aligned}
$$

Some students are used to get high grades in the high school, but the situation may change at the university. The different backgrounds of the students also causes challenges for the curriculum design work. While setting the learning outcomes the teachers need to pay attention to the students having different levels of preliminary knowledge and interest.

The third internal stakeholder was the teachers' own community whose activities and aims strongly guided the curriculum design work. The teachers participating in the session had a unique way of doing curriculum design work. They were actively reflecting on, developing and improving their curriculum by concentrating specifically on learning outcomes. Teachers' personal opinions and views were appreciated:

Jack: And it may seem like that we have roughly same understanding of things, but

it naturally isn't so because everyone has his own way of thinking and own views.

In the context of teachers' own community, the participants also had recognised roles and responsibilities which they were expected to perform. Overall, the working method used in the session was familiar to the teachers, ensuring the successful collaboration between them. 


\subsection{External stakeholders}

Together with internal stakeholders, there are also external stakeholders influencing curriculum design work. The role of labour market and higher education policy, specifically, caused many debates in the session. The labour market was seen as a purely positive stakeholder. The teachers clearly stated that labour market is very closely related to teaching and research and they felt that it is important to acknowledge its role in the modern world.

Brian: The important part of our research is to understand what the real world is and what kinds of demands it has. The users of the products are very close to us meaning that it is absolutely not a limitation or burden but a strength. It makes this work meaningful and rich.

By contrast, the higher education policy was seen as a negative stakeholder in terms of curriculum design work. The participant teachers described it as a limiting factor that determined the direction of curriculum development. The teachers find it contradictory that even though higher education policy is distinct and distant from curriculum per se, the policy decisions and the reasoning supporting those decisions still have such a strong influence on curriculum design work. It was seen as problematic that young people are politically steered to come to the university directly from the high school without any work experience:

Brian: In the Finnish higher education policy, it has been decided that young people have to start their university studies without any work experience or taking a year off.

The higher education policy also aims to promote graduating as fast as possible. Enhancing fast graduation does not support the acquisition of work experience during the studies, which may cause difficulties for graduates in their integration into the labour market.

\section{CONCLUSIONS AND DISCUSSION}

The paper was based on higher education teachers' perceptions about the impacts that various stakeholders have on product development curriculum design. In general, the stakeholders were considered to have either positive, negative or neutral role in curriculum design work. The faculty and higher education policy were seen as negative stakeholders having a too dominant role in curriculum design. While being seen as a distant stakeholder, the teachers thought that higher education policy is still making relatively heavy demands on practical curriculum work. The role of the students was also seen in a rather negative light because of their weak preliminary knowledge and skills as well as flawed attitudes towards university studies.

The participant teachers treated labour market as a very positive stakeholder having a close relationship with teaching and research. It was seen as highly important that teachers' and students' collaboration with the labour market was constantly taken into account in curriculum design. A neutral stakeholder influencing on curriculum design work was the teachers' own community which made the practical decisions on curriculum-related matters. The teachers had obvious and well-established roles and responsibilities, which seemed to facilitate the execution of curriculum development session. In this paper, the curriculum was not only seen as a tool for pedagogical activity, but also as a subject of codevelopment and collaboration between various stakeholders. Seen from teachers' point of view, the ways in which different stakeholders are involved in curriculum design work are shown in Figure 2.

In Figure 2, the stakeholders' involvement is described from the teachers' perspective, who participated in the curriculum development session. While doing curriculum design work, the teachers took into account of their collaboration with various other stakeholders. The teachers saw themselves collaborating directly with the three stakeholders: labour market, students and faculty. By contrast, the teachers' collaboration with higher education policy was seen to occur indirectly, via faculty. The participant teachers' own community was based on collegiality with shared principles and values [18]. Jarzabkowski [19] explores the notion of collegiality as a form of teacher culture and uses the term to describe teachers' involvement with their peers on intellectual, moral, political, social and/or emotional level(s). All members of community were involved in joint problem solving and decision-making, simultaneously showing their willingness to contribute to the development of curriculum. 


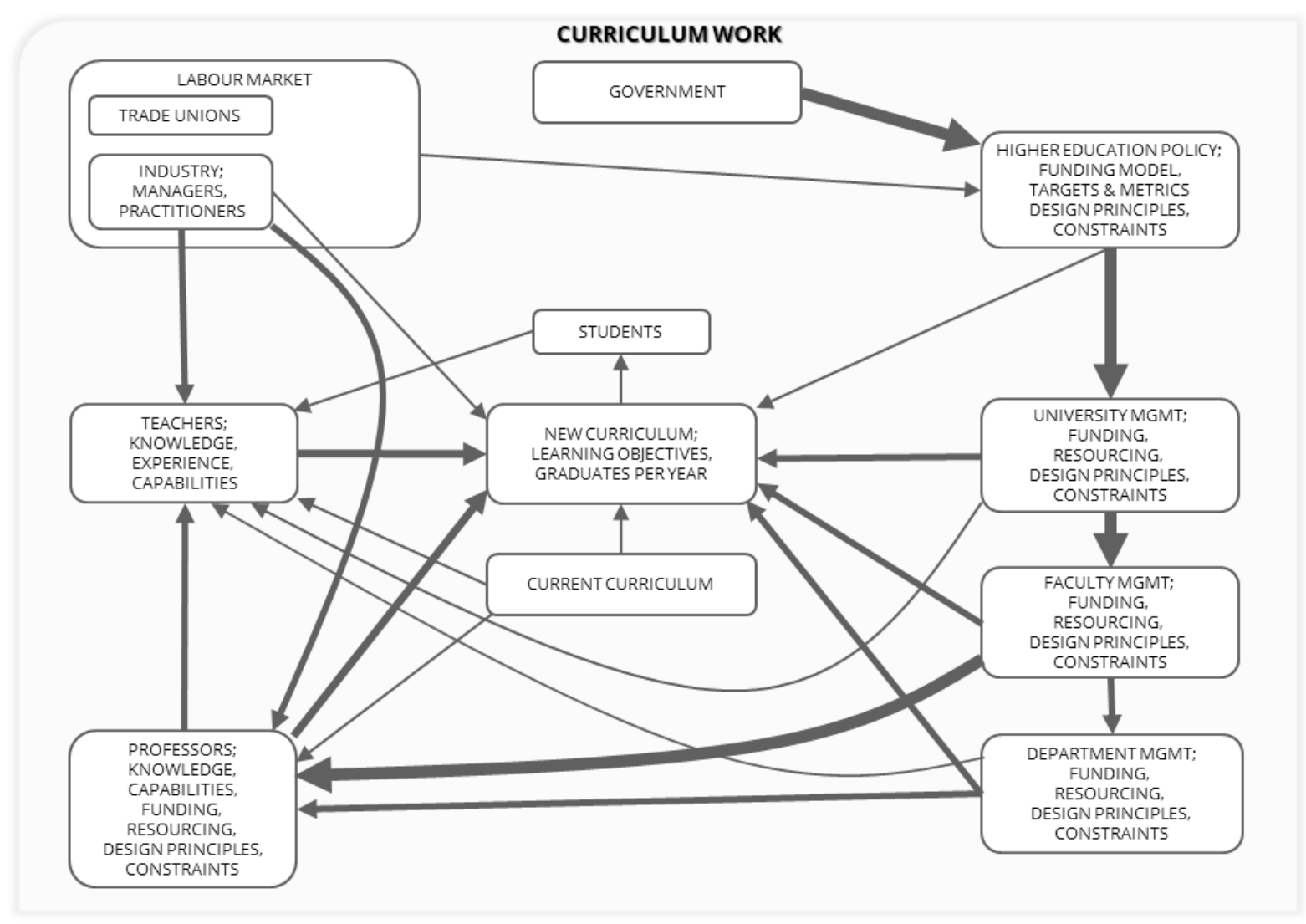

Figure 2. Stakeholders' involvement in curriculum design work from teachers' point of view

This paper has identified the various stakeholders and the ways in which they influence curriculum design work. The paper is written from the perspective of only one stakeholder, the teachers' own community. Olsen and Maassen [20] note that faculty, students, and administrators presumably have different views on the issues of curriculum design. For this reason, a greater involvement of also other relevant stakeholders would be important in order to create a more comprehensive understanding of curriculum and its development. However, the research results presented here are useful to all participants involved in curriculum design work: students, faculty, teachers, higher education policy, research community, and labour market.

\section{REFERENCES}

[1] Blackmore P. and Kandiko C.B. (2012) 'Change: Processes and resources', in Blackmore, P. and Kandiko, C. B. (eds) Strategic Curriculum Change. Global Trends in Universities. London:

Taylor and Francis, pp. 111-209.

[2] Voogt J.M., Pieters J.M. and Handelzalts A. (2016) 'Teacher collaboration in curriculum design teams: effects, mechanisms, and conditions', Educational Research and Evaluation, 22 (3), pp. 121-140.

[3] Pareja Roblin N.N., Ormel B.J.B., McKenney S.E., Voogt J.M. and Pieters J. M. (2014) 'Linking research and practice through teacher communities: A place where formal and practical knowledge meet?', European Journal of Teacher Education, 37, pp. 183-203.

[4] Morris A.K. and Hiebert J. (2011) 'Creating shared instructional products: An alternative approach to improving teaching', Educational Researcher, 40, pp. 5-14.

[5] Juuti T., Lehtonen T., Rättyä K., Halonen N., Vanhatalo M. and Kujansuu P. (2014) 'Design Reasoning Patterns in NPD Education Design', DS 78: Proceedings of the 16th International conference on Engineering and Product Design Education (E\&PDE14). University of Twente, The Netherlands, 4-5 September. Available at: https://www.designsociety.org/publication/35960/Design+Reasoning+Patterns+in+NPD+Educati on+Design (Accessed: 11 March 2019).

[6] Nevaranta J. (2014) Competence Needs and a Model for the Teaching Strategy Development of 
Mechanical Designers in Product Development. Thesis for the degree of Doctor of Science in Technology. Tampere University of Technology. Available at:

https://tutcris.tut.fi/portal/files/1465506/nevaranta.pdf (Accessed: 11 March 2019).

[7] Whitchurch C. (2010) 'Some implications of 'public/private' space for professional identities in higher education', Higher Education 60 (6), pp. 627-640.

[8] Matkovic P., Tumbas P., Sakal M. and Pavlićević V. (2014) 'University Stakeholders in the Analysis Phase of Curriculum Development Process Model', Proceedings of ICERI2014 Conference. Seville, Spain, 17-19 November.

[9] Snape D. and Spencer L. (2003) 'The Foundations of Qualitative Research', in Ritchie, J. and Lewis, J. (eds) Qualitative Research Practice. A guide for Social Science Students and Researchers. London: SAGE, pp. 1-23.

[10] Anderson G. (1990) Fundamentals of Educational Research. Hampshire: The Falmer Press.

[11] Atkins L. and Wallace S. (2012) Qualitative Research in Education. London: SAGE Publications.

[12] Woodside A.G. (2010) Case Study Research: Theory. Methods. Practice. Bingley: Emerald.

[13] Stake R.E. (1995) The Art of Case Study Research. Thousand Oaks: SAGE Publications.

[14] Hsieh H.-F. and Shannon S.E. (2005) 'Three Approaches to Qualitative Content Analysis', Qualitative Health Research, 15 (9), pp. 1277-1288. https://doi.org/10.1177/1049732305276687

[15] Assarroudi A., Heshmati Nabavi F., Armat M.R., Ebadi A. and Vaismoradi M. (2018) 'Directed qualitative content analysis: the description and elaboration of its underpinning methods and data analysis process', Journal of Research in Nursing, 23 (1), pp. 42-55. https://doi.org/10.1177/1744987117741667

[16] Potter W.J. and Levine-Donnerstein D. (1999) 'Rethinking validity and reliability in content analysis', Journal of Applied Communication Research, 27 (3), pp. 258-284. https://doi.org/10.1080/00909889909365539

[17] Mayring P. (2000) 'Qualitative Content Analysis', Forum: Qualitative Social Research, 1 (2), Available at: http://www.qualitative-research.net/index.php/fqs/article/view/1089/2386 (Accessed: 11 March 2019).

[18] Välimaa J. (2017) 'Yhteisiä päätöksiä vai johtajavaltaisuutta? Kollegiaalisuus yliopistojen perustana' Niin \& Näin, 24 (4), pp. 47-51. Available at: https://www.netn.fi/sites/www.netn.fi/files/netn174-07.pdf (Accessed: 11 March 2019).

[19] Jarzabkowski L.M. (2002) 'The social dimensions of teacher collegiality', Journal of Educational Enquiry, 3 (2), pp. 1-20.

[20] Olsen J.P. and Maassen P. (2007) 'European Debates on the Knowledge Institution: The Modernisation of the University at the European Level', in Maassen, P. and Olsen, J. P. (eds) University Dynamics and European Integration. Dordrecht: Springer, pp. 3-22. 